\title{
Cellulose nanocrystals from grape pomace: Production, properties and cytotoxicity assessment
} \author{
Lourdes M.C. Cabral ${ }^{\mathrm{a}, \mathrm{b}}$, José A. Teixeira ${ }^{\mathrm{c}}$ \\ a PPGCAL/Instituto de Química, UFRJ, Cidade Universitária, Ilha do Fundão, 21949-900, Rio de Janeiro, RJ, Brazil \\ ${ }^{\mathrm{b}}$ Embrapa Agroindústria de Alimentos, Av. das Américas 29501, 23020-470, Rio de Janeiro, RJ, Brazil \\ ${ }^{c}$ Centre of Biological Engineering, Universidade do Minho, Campus de Gualtar, 4710-057, Braga, Portugal \\ d International Iberian Nanotechnology Laboratory, Av. Mestre José Veiga s/n, 4715-330, Braga, Portugal
}

Caroline C.S. Coelho ${ }^{\mathrm{a}, \mathrm{b}, \mathrm{c}}$, Michele Michelinn ${ }^{\mathrm{c}, *}$, Miguel A. Cerqueira ${ }^{\mathrm{d}}$, Catarina Gonçalves ${ }^{\mathrm{d}}$, Renata V. Tonon ${ }^{\mathrm{a}, \mathrm{b}}$, Lorenzo M. Pastrana ${ }^{\mathrm{d}}$, Otniel Freitas-Silva ${ }^{\mathrm{b}}$, António A. Vicente ${ }^{\mathrm{c}}$,

\section{A R T I C L E I N F O}

\section{Keywords:}

Lignocellulosic

Pretreatment

Biopolymer

Nanotechnology

\begin{abstract}
A B S T R A C T
Cellulose nanocrystals (CNCs) were obtained from grape pomace through chemical and physical pretreatments Bleached cellulose pulp was subjected to acid hydrolysis (AH) for 30 or $60 \mathrm{~min}$ and an ultrasound treatment to obtain $\mathrm{CNCs}\left(\mathrm{AH}_{30 \mathrm{~s}}\right.$ and $\left.\mathrm{AH}_{60 \mathrm{~S}}\right)$. Compositional analyses of untreated (UGP) and pretreated (PGP) grape pomace showed the effectiveness of pretreatment in removing non-cellulosic components, recovering $80.1 \%$ cellulose in PGP (compared to $19.3 \%$ of UGP). Scanning and transmission electron microscopies were used to evaluate the CNCs morphology. AH in combination with ultrasound treatment led to needle-shaped structures and apparently more dispersed suspensions. Crystallinity index and thermal stability were studied by X-ray diffraction and thermogravimetric analysis, respectively. The $\mathrm{AH}_{60 \text { s }}$ sample presented high aspect ratio, crystallinity and thermal stability. CNCs toxicity was evaluated by exposing Caco-2 cells to CNCs suspension and evaluating their viability. Results showed that CNCs are non-toxic, opening the opportunity for their use on food and pharmaceutical applications.
\end{abstract}

\section{Introduction}

A key issue for a sustainable agriculture is the rational use of residues and by-products from the agricultural processes. Viticulture generates each year nine million tons of pomace, which is about $20 \%$ $(w / w)$ of the total grapes used for wine production (Goula, Thymiatis, \& Kaderides, 2016; Teixeira, Baenas, Dominguez-perles, Barros, \& Rosa, 2014). Thus, the development of new strategies for the use of grape pomace can minimize their environmental impact and, at the same time, add value to this residue.

Grape pomace consists mainly of polysaccharides from plant cell wall, such as cellulose (Beres et al., 2016; Minjares-Fuentes et al., 2016), representing an interesting source to produce new materials, as cellulose nanocrystals (CNCs). Lu and Hsieh (2012b) and Hsieh (2013) reported the production of CNCs from natural resources, such as grape skin. CNCs are highly crystalline cellulose nanostructures presenting interesting properties, such as: low density, surface reactivity, high aspect ratio and surface area, high biocompatibility and biodegradability (Brinchi, Cotana, Fortunati, \& Kenny, 2013), moving a millionaire market. According to Market and Market (2018), the nanocellulose market is forecasted to achieve $\$ 250$ Million by 2019. The rising demand and the use in novel applications have driven the researchers and the industry to explore even more the use of nanocellulose.

Currently, acid hydrolysis and physical processes are widely used for the production of CNCs from cellulosic materials (Lu \& Hsieh, 2010, 2012a, 2012b; Johar, Ahmad, \& Dufresne, 2012; Jiang \& Hsieh, 2013; Oun \& Rhim, 2015; Moriana, Vilaplana, \& Ek, 2016). Depending on the composition of the raw cellulose, pretreatment, and disintegration process used, CNCs with different features are obtained, such as diameter, length, crystallinity index and thermal decomposition temperature.

In the last years different approaches have been presented for the production of CNCs. Reddy and Rhim (2014) studied the CNC production from mulberry paper pulp by acid hydrolysis followed by ultrasound treatment, resulting in mulberry pulp CNC with stem or spherical shape with a diameter of $40-50 \mathrm{~nm}$ and a length of 200-350 nm. Kallel et al. (2016) also reported acid hydrolysis followed

\footnotetext{
* Corresponding author.

E-mail address: mimichelin@ceb.uminho.pt (M. Michelin).
} 


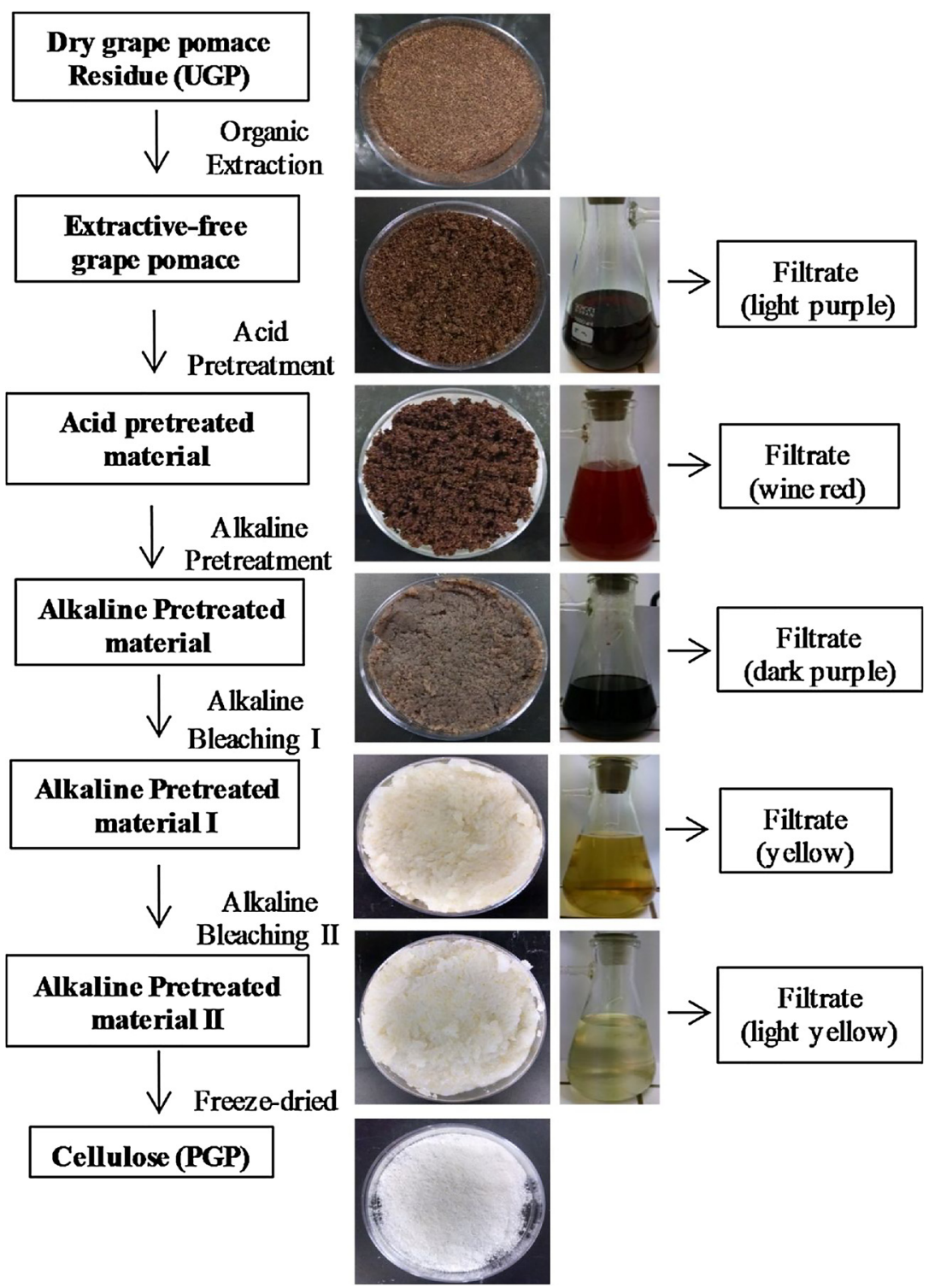

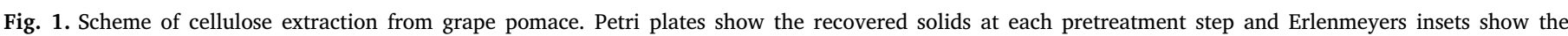
corresponding filtrates.

by ultrasound treatment to obtain CNC from garlic straw residues; the CNCs obtained showed a needle-like structure with a mean diameter of $6 \mathrm{~nm}$ and length of $480 \mathrm{~nm}$. Li, Yue, and Liu (2012) investigated the production of CNC through ultrasound treatment from microcrystalline cellulose. The use of ultrasound resulted in CNCs with a rod-shaped structure with diameters between 10 and $20 \mathrm{~nm}$ and lengths between 50 and $250 \mathrm{~nm}$. Despite the studies carried out involving the CNCs production from cellulose, only few studies investigated the chemical composition of the lignocellulosic material (LCM) used, as well as the purity of the cellulose used to produce the CNCs. Additionally, in the case of using grape pomace this has never been performed.

Despite the potential benefits of using materials at nanoscale, there are concerns arising from related properties, such as their nano-dimension, large surface area and high reactivity, that may represent a health threat to humans and other organisms (Prasad, Bhattacharyya, \& Nguyen, 2017). In fact, and according to the application (e.g. food), the toxicological assessment of nanomaterials is essential and should be addressed. Although several studies in the past decade have resulted in the development of CNCs with good structural properties from several sources (Jiang \& Hsieh, 2013, 2015; Lu \& Hsieh, 2012a, 2012b; Mueller, Weder, \& Foster, 2014; Rosa et al., 2010), only few works focused on the toxicity evaluation of these products.

In this sense, this study aimed at obtaining CNCs from Pinot Noir grape pomace, evaluating of the effect of acid hydrolysis and ultrasound treatments in their structure and physicochemical properties. The chemical composition of the raw material and cellulose obtained after the pretreatment steps, which was used to obtain the CNCs, was determined. In the end, the possible toxicity of CNCs was also evaluated.

\section{Experimental}

\subsection{Materials}

Pinot Noir grape pomace, from the white wine vinification process, was kindly donated by the Aurora winery (Bento Gonçalves, RS, Brazil). The material was transported frozen and stored at $-18{ }^{\circ} \mathrm{C}$ until processing. Minimum essential medium (MEM) was purchased from Thermo Scientific (United Kingdom). Penicillin/streptomycin, fetal bovine serum (FBS) and non-essential amino acids were purchased from Millipore (Germany). PrestoBlue was acquired from Invitrogen (USA). Sodium pyruvate was purchased from Sigma-Aldrich. Ethanol (96\% v/ v, Panreac, Spain), sulfuric acid (95\%-98\% w/w, Fisher Chemical, 
Portugal), sodium hydroxide (98.5\%, José Manuel Gomes dos Santos Lda, Portugal), hydrogen peroxide (30\% weight, Chem-Lab, Belgium) were used as received without further purification. The water used was purified by Milli-Q plus water purification system (Millipore Corporate, Billerica, USA).

\subsection{Extraction of cellulose from grape pomace}

Pinot Noir grape pomace was dried at $60^{\circ} \mathrm{C}$ for $18 \mathrm{~h}$. After that, the dried material was processed in a depulper (Bonina $0.25 \mathrm{df}$, Itametal, Brazil), where the seeds were trapped in the strainer, and the pomace was milled (IKA grinder, A11, Staufen, Germany) and sieved to pass through a 40-mesh screen (untreated grape pomace, UGP). UGP was conditioned in vacuum-sealed plastic bags, stored at room temperature and protected from light.

Cellulose was extracted from UGP through the removal of non-cellulosic components according to the procedure reported by $\mathrm{Lu}$ and Hsieh (2012b) with some modifications. Firstly, extractives (e.g. wax, phenolics, pigments and oils) were removed from dried UGP in a $2 \mathrm{~L}$ stainless steel reactor (Parr Instruments Company, Series 4520 Bench Top Reactor, Moline, Illinois, USA), using ethanol (0.067 $\mathrm{g} \mathrm{UGP} / \mathrm{mL})$ at $120^{\circ} \mathrm{C}$ for $1 \mathrm{~h}$. The recovered solid material was oven-dried at $70{ }^{\circ} \mathrm{C}$ for $24 \mathrm{~h}$ and then pretreated with $2 \% \mathrm{H}_{2} \mathrm{SO}_{4}(0.05 \mathrm{~g} / \mathrm{mL})$ under constant stirring at $90^{\circ} \mathrm{C}$ for $5 \mathrm{~h}$ to hydrolyze acid-soluble polysaccharides and polyphenolics. After that, it was filtered and washed with water until neutral $\mathrm{pH}$. The acid pretreated material was further leached with $5 \%$ $\mathrm{NaOH}(0.05 \mathrm{~g} / \mathrm{mL})$ at room temperature for $10 \mathrm{~h}$ and continued at $90{ }^{\circ} \mathrm{C}$ for $5 \mathrm{~h}$ to dissolve remaining hemicellulose, lignin and other alkali-soluble polysaccharides. The alkaline pretreated material was filtered and thoroughly washed with water until neutral $\mathrm{pH}$. After that, this material was bleached by $5 \% \mathrm{H}_{2} \mathrm{O}_{2}(0.05 \mathrm{~g} / \mathrm{mL}), \mathrm{pH} 11.5$ (adjusted with $\mathrm{NaOH}$ ), at $50{ }^{\circ} \mathrm{C}$ for $8 \mathrm{~h}$, then cooled to room temperature for $15 \mathrm{~h}$ to oxidize and dissolve residual lignin and phenolics. The bleaching effect was enhanced by an additional bleaching step for a further $8 \mathrm{~h}$, as described previously. The final product was washed with water until neutral $\mathrm{pH}$ and the resulting aqueous suspension was quickly frozen at $-80^{\circ} \mathrm{C}$ in a sample container and freeze-dried (Alpha 1-4 LD plus, Martin Christ, Germany).

The recovered cellulose was designated as PGP (pretreated grape pomace). Fig. 1 is a schematic representation of the process. To calculate the yield, the initial dry mass of UGP used for the cellulose extraction process and the final dry mass of PGP were taken into account.

\subsection{Cellulose hydrolysis}

Cellulose isolated from grape pomace was hydrolyzed using 64-65 wt\% sulfuric acid ( $0.05 \mathrm{~g}$ cellulose $/ \mathrm{mL})$ at $45{ }^{\circ} \mathrm{C}$, under mechanical stirring, for $30 \mathrm{~min}$ or $60 \mathrm{~min}$, and named $\mathrm{AH}_{30}$ and $\mathrm{AH}_{60}$, respectively. The times used for acid hydrolysis were based on the literature; a maximum of 60 min was used to avoid a longer reaction time and the prolonged exposure of cellulosic materials to acid, once it could lead to the digestion of the crystalline domains of PGP and thus to a decrease in the crystallinity of CNCs (Martínez-Sanz, Lopez-Rubio, \& Lagaron, 2011). The acid hydrolysis was stopped by diluting it 10-fold with ice water. The recovered material was washed with water until to $\mathrm{pH} 4.0$, when a colloidal suspention was formed. This suspention (supernatant) was dialyzed using regenerated cellulose dialysis membranes with $8 \mathrm{kDa}$ molecular weight cut off (Orange Scientific, Belgium) against ultrapure water until reaching neutral $\mathrm{pH}$. After that, $\mathrm{AH}_{30}$ and $\mathrm{AH}_{60}$ samples were processed with a probe-type ultrasound (Vibra Cell $^{\mathrm{TM}}$ Sonicator, USA) in an ice bath for $10 \mathrm{~min}$ (cycles of $5 \mathrm{~s}$ on and $2 \mathrm{~s}$ off), at $40 \%$ power, and named $\mathrm{AH}_{30 \mathrm{~s}}$, and $\mathrm{AH}_{60 \mathrm{~s}}$, respectively.

The samples were kept refrigerated $\left(7^{\circ} \mathrm{C}\right)$ for stability studies and transmission electron microscopy (TEM) or freeze-dried (Alpha 1-4 LD plus, Martin Christ, Germany) for scanning electron microscopy (SEM), thermogravimetric, X-ray diffraction and toxicity analyses. The initial dry mass of PGP (cellulose) used in the acid hydrolysis and the final mass after freeze-drying were taken into account to calculate the yield.

\subsection{Characterization}

\subsubsection{Compositional analysis}

Solid materials (UGP and PGP) were milled and/or sieved to a particle size of 40 mesh for compositional analysis. Approximately $0.3 \mathrm{~g}$ of material was hydrolyzed with $3 \mathrm{~mL}$ of $72 \%$ (w/w) $\mathrm{H}_{2} \mathrm{SO}_{4}$ for $1 \mathrm{~h}$ at $30{ }^{\circ} \mathrm{C}$, followed by a quantitative post-hydrolysis with $4 \%$ (w/w) $\mathrm{H}_{2} \mathrm{SO}_{4}$ (by adding $84 \mathrm{~g}$ of ultrapure water) at $121^{\circ} \mathrm{C}$ during $60 \mathrm{~min}$. After hydrolysis, the insoluble material was recovered by filtration and dried at $105^{\circ} \mathrm{C}$, while the hydrolysates were quantified by high-performance liquid chromatography (HPLC) regarding to monosaccharides content (glucose, xylose and arabinose) and acetic acid. Klason lignin was considered the insoluble material minus ash and protein contents. For determination of ash content, the solid material was taken in a crucible and kept in a muffle furnace at $575^{\circ} \mathrm{C}$ for $24 \mathrm{~h}$ (Sluiter et al., 2008). The protein content was calculated based on the nitrogen content estimated with Kjeldahl method, multiplied by a factor of 6.25 .

2.4.1.1. High-performance liquid chromatography (HPLC). Acid hydrolysates were filtered through $0.45 \mu \mathrm{m}$ syringe filter and automatically injected (JASCO Intelligent Sampler AS 2057 Plus) in a Metacarb $87 \mathrm{H}$ column $(300 \times 7.8 \mathrm{~mm}$, Varian, USA $)$ preheated to $60^{\circ} \mathrm{C}$ by a thermostatic column compartment (Chrompack Instruments AG, Neuheim, Switzerland). The mobile phase $\left(0.005 \mathrm{M} \mathrm{H}_{2} \mathrm{SO}_{4}\right.$ in ultrapure water filtered through $0.2 \mu \mathrm{m}$ Millipore ${ }^{\circ}$ nylon filter and degassed) was pumped at a flow rate of $0.6 \mathrm{~mL} / \mathrm{min}$ through a JASCO $880 \mathrm{PU}$ pump. Sugars and acetic acid were analyzed with a refractive index (RI) detector.

\subsubsection{Transmission electron microscopy (TEM)}

A drop of $10 \mu \mathrm{L}$ of the samples were deposited onto TEM grids (ultra-thin carbon film on Lacey carbon support film, 400 mesh, Copper, Ted Pella Inc., USA) and the liquid excess was removed with a filter paper after $2 \mathrm{~min}$. The samples were observed using a JEM-2100 transmission electron microscope (JEOL, Japan) operated at a $200 \mathrm{kV}$ accelerating voltage. TEM micrographs were analyzed using the public domain software Image $J$ and the size and aspect ratio of the samples were calculated. A minimum of 30 measurements was performed for each analysis.

\subsubsection{Scanning electron microscopy (SEM)}

The samples' surface morphology was evaluated through SEM using a Quanta FEG 650 (FEI USA). Dry samples were affixed on aluminum stubs covered by carbon ribbon, and then coated with gold and observed using an accelerating voltage of $5 \mathrm{kV}$ under vacuum conditions.

\subsubsection{Stability of the samples}

Stability of the cellulose suspensions obtained after acid hydrolysis $\left(\mathrm{AH}_{30}\right.$ and $\left.\mathrm{AH}_{60}\right)$ and acid hydrolysis plus ultrasonic treatment $\left(\mathrm{AH}_{30 \mathrm{~s}}\right.$ and $\mathrm{AH}_{60 \mathrm{~s}}$ ) was analyzed after $30 \mathrm{~min}$ and 7 days' storage at $7{ }^{\circ} \mathrm{C}$, through the observation of precipitate formation or the maintenance of the homogeneous suspension.

\subsubsection{X-ray diffraction (XRD)}

Crystallinity of the samples was determined by XRD, using a Bruker D8 Discover diffractometer equipped with $\mathrm{Ni}$ filtered $\mathrm{Cu}-\mathrm{Kb}$ radiation source of $40 \mathrm{kV}$ and $40 \mathrm{~mA}$. Samples were scanned in the range of 5-50

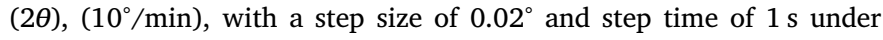
room temperature. The crystallinity index $(\mathrm{CrI})$ was determined according to Segal, Creely, Martin Jr, and Conrad (1959), using the Eq. (1). 
$C r I=\frac{I_{002}-I_{a m}}{I_{002}} \times 100$

where $I_{O O 2}$ is the intensity of maximum diffraction of crystalline region at about $2 \theta=22.5^{\circ}$, and $I_{a m}$ is the intensity of diffraction attributed to the amorphous region at about $2 \theta=18^{\circ}$.

\subsubsection{Thermogravimetric analysis (TGA)}

TGA was performed using a thermogravimetric analyzer PerkinElmer 4000 (PerkinElmer, Portugal). About $8.5 \mathrm{mg}$ of the samples were loaded in ceramic pan and heated from 20 to $550{ }^{\circ} \mathrm{C}$ at a heating rate of $20^{\circ} \mathrm{C} / \mathrm{min}$ under a nitrogen atmosphere. The samples' weight loss was recorded as a function of temperature and characterized by a TG curve. The derivative thermogravimetric (DTG) curve was used to emphasize the temperature zone where each phenomenon occurred.

\subsubsection{Cytotoxicity assessment}

The cellular compatibility of $\mathrm{AH}_{30 \mathrm{~S}}$ and $\mathrm{AH}_{60 \mathrm{~S}}$ samples was assessed using the Caco-2 human colon epithelial cancer cells (ATCC, HTB-37) and PrestoBlue (Nowak et al., 2017). The cells (passage 25-30) were cultured in minimum essential medium (MEM), supplemented with $20 \%$ fetal bovine serum, $0.11 \mathrm{~g} / \mathrm{L}$ sodium pyruvate, $1 \%$ non-essential amino acids and $1 \%$ penicillin/streptomycin. The cells were kept at $37^{\circ} \mathrm{C}$ and $5 \% \mathrm{CO}_{2}$. For the cell viability assay, Caco- 2 cells were seeded onto 96-wells plates at a density of 10,000 cells per well and left adhering overnight. After adhesion, the culture medium was removed and replaced by the samples diluted in the culture medium at different final concentrations: $0.05 \mathrm{mg} / \mathrm{mL}$ and $0.20 \mathrm{mg} / \mathrm{mL}$.

Samples were dispersed in ultrapure water using magnetic stirring, followed by a treatment with ultrasonic bath during $15 \min (37 \mathrm{KHz}$ and $104 \mathrm{~W}$ ), and exposed to ultraviolet light during $30 \mathrm{~min}$ for sterilization. The water dispersions of samples were diluted in the culture medium $(20 \%, v / v)$ to obtain the test concentrations. A negative control was performed using cells growing in the culture medium with $20 \%$ (v/v) of ultrapure water (considered as $100 \%$ cell viability). The $30 \%$ DMSO was used as a positive control. The samples were incubated for $24 \mathrm{~h}$ or $48 \mathrm{~h}$ with $10 \%$ PrestoBlue, a resazurin-based solution (final concentration $0.01 \mathrm{mg} / \mathrm{mL}$ ), is a cell permeable redox indicator used for cell viability in proliferation and cytotoxicity assays (Nociari, Shalev, Benias, \& Russo, 1998). PrestoBlue was added simultaneously with samples, since resazurin is not toxic, to provide adequate sensitivity (Ansar Ahmed, Gogal Jr, \& Walsh, 1994; Xu, McCanna, \& Sivak, 2015).

The fluorescence intensity, that is proportional to the cell viability, was measured using a Microplate Fluorescence Reader (Synergy, BioTek H1, USA) at an excitation wavelength of $560 \mathrm{~nm}$ and an emission wavelength of $590 \mathrm{~nm}$. The percentage of cell viability was expressed as the percentage of fluorescence in treated cells (samples at different concentrations) in relation to the percentage of fluorescence of cells growing in the culture medium with $20 \%(\mathrm{v} / \mathrm{v})$ ultrapure water.

\section{Results and discussion}

\subsection{Isolation of cellulose}

Cellulose from grape pomace was extracted through a five-step of pretreatment including organic solvent extraction, acid and alkaline pretreatments, and two consecutive bleaching steps, as presented in Fig. 1 (the light-yellow color of the pulp after bleaching II probably results from the remaining lignin). Each $100 \mathrm{~g}$ of UGP led to $10.2 \mathrm{~g}$ of pretreated grape pomace (PGP), most of which consisted of cellulose $(80.1 \%)$, being the non-cellulose components such as hemicellulose and lignin, efficiently removed from UGP (Table 1). The obtained extraction yield $(\approx 10 \%)$ was lower than the value reported by Lu and Hsieh, (2012b), which obtained an extraction yield of $16.4 \%$ for cellulose from grape skin using a similar extraction protocol. However, Jiang and
Hsieh (2015) presented extraction yields in the same range of values obtained in this work. They used acidified $\mathrm{NaClO}_{2} / \mathrm{KOH}$ route or alkaline $\mathrm{NaOH} / \mathrm{H}_{2} \mathrm{O}_{2}$ route to pretreat tomato peels and obtained yields of $13.1 \%$ and $11.3 \%$, respectively. These results show the influence of the type of residue and the extraction process used in the extraction yield.

Results presented in Table 1 show that this process satisfactorily allowed the extraction of cellulose from untreated grape pomace (UGP) for the further acid treatment, allowing the access of the acid to the amorphous structure of cellulose, which is blocked by large amounts of hemicellulose and lignin.

\subsection{Cellulose nanocrystals yield}

Grape pomace cellulose (PGP containing $80.1 \%$ of cellulose) was hydrolyzed with $64-65 \mathrm{wt} \%$ sulfuric acid for $30 \mathrm{~min}\left(\mathrm{AH}_{30}\right)$ or $60 \mathrm{~min}$ $\left(\mathrm{AH}_{60}\right)$ and microcrystalline cellulose (MCC) was obtained. Production of MCC from cellulose by using mineral acids, such as sulfuric acid, was also reported by Thoorens, Krier, Leclercq, Carlin, and Evrard (2014). The samples $\left(\mathrm{AH}_{30}\right.$ and $\left.\mathrm{AH}_{60}\right)$ containing MCC were submitted to an ultrasound treatment $\left(\mathrm{AH}_{30 \mathrm{~s}}\right.$ and $\left.\mathrm{AH}_{60 \mathrm{~S}}\right)$ to obtain the CNCs (see Section 3.3). The CNCs yields for $\mathrm{AH}_{30 \text { s }}$ and $\mathrm{AH}_{60 \text { s }}$ were $27.56 \%$ and $20.96 \%$, respectively. These values are higher than that reported in other works. Jiang and Hsieh (2015) reported a yield of $15.7 \%$ for CNCs obtained from tomato peel cellulose, while Lu and Hsieh (2012a) reported a yield of $6.4 \%$ for CNCs from rice straw cellulose, using similar conditions. Many factors can influence the CNCs yield, such as acid concentration, reaction time, cellulose amount per acid volume used in the process (Nascimento et al., 2016) and the purity of cellulose (Xie et al., 2016). In this case, the highest yield obtained in this study may be associated to the lower cellulose concentration used in this work, $0.05 \mathrm{~g} / \mathrm{mL}$, compared to $0.114 \mathrm{~g} / \mathrm{mL}$ used in the other works (Jiang \& Hsieh, 2015; Lu \& Hsieh, 2012a). The lower cellulose concentration leads to a higher effect of the acid in its amorphous parts, improving cellulose depolymerization and therefore increasing CNCs yield.

\subsection{Transmission electron microscopy analysis}

The size and morphology of the samples obtained after acid hydrolysis $\left(\mathrm{AH}_{30}\right.$ and $\left.\mathrm{AH}_{60}\right)$ and further ultrasound treatment $\left(\mathrm{AH}_{30 \mathrm{~s}}\right.$ and $\mathrm{AH}_{60 \mathrm{~S}}$ ) observed by TEM suggest that acid hydrolysis provided partial depolymerization of cellulose into MCC (Fig. 2A and C), while ultrasound led to a disaggregation of MCC forming the cellulose nanocrystals - CNCs (Fig. 2B and D). The cavitation generated by ultrasound can disrupt the interactions in the cellulose matrix, essentially connected through hydrogen bonds. Thus, ultrasound makes cellulose in the liquid environment to be intensely agitated, allowing a change in its network (Chen et al., 2011).

In $\mathrm{AH}_{30 \text { s }}$ and $\mathrm{AH}_{60 \text { s }}$ samples needle-shaped structures were obtained, with a typical CNC morphology, as reported elsewhere (Jiang \& Hsieh, 2015; Martins et al., 2015; Teixeira et al., 2011). The needleshaped CNCs showed lengths of $307 \mathrm{~nm}$ and $323 \mathrm{~nm}$ and diameters of $8 \mathrm{~nm}$ and $7 \mathrm{~nm}$ for $\mathrm{AH}_{30 \mathrm{~s}}$ and $\mathrm{AH}_{60 \mathrm{~s}}$ samples, respectively, reproducing $\mathrm{L} / \mathrm{D}$ ratios of 38 and 46 . These result allow their classification as CNCs, which according to TAPPI, Standard Terms and Their Definition for Cellulose Nanomaterial, WI 3021 (2011), must present diameters between 3 and $10 \mathrm{~nm}$ and a L/D ratio higher than 5. Martínez-Sanz et al. (2011) reported similar L/D values for CNCs obtained from bacterial cellulose. The diameter and length of CNCs decreased for higher treatment time (from $2 \mathrm{~h}$ to $69 \mathrm{~h}$ of acid hydrolysis and further neutralization), however the L/D values of CNCs did not change.

The structure and properties, particularly the length and diameter of CNCs, depend on several factors such as the source of the original cellulose and the extraction process, which includes all pretreatments and disintegration or deconstruction processes (Moon, Martini, Nairn, Simonsen, \& Youngblood, 2011; Peng, Gardner, \& Han, 2012). Studies 
Table 1

Chemical composition of untreated (UGP) and pretreated grape pomace (PGP), expressed as percentage of dry raw material weight.

\begin{tabular}{|c|c|c|c|c|c|c|}
\hline Samples & Cellulose $^{\mathrm{a}}(\%)$ & Hemicellulose (\%) & Klason lignin (\%) & Protein (\%) & Ash (\%) & Others $^{\mathrm{b}}(\%)$ \\
\hline UGP & $19.30 \pm 0.67$ & $7.20 \pm 0.50$ & $15.60 \pm 0.28$ & $17.29 \pm 0.02$ & $3.58 \pm 0.24$ & 37.03 \\
\hline PGP & $80.10 \pm 1.75$ & n.d. & $4.30 \pm 2.55$ & $0.35 \pm 0.03$ & $4.71 \pm 0.51$ & 10.54 \\
\hline
\end{tabular}

n.d.: not detected.

a Estimated from the glucan content.

b Calculated by difference (includes unidentified components).

on morphology of cellulose nanoparticles obtained from different sources have shown tendency to aggregate, presenting high L/D ratio (Chen, Liu, Chang, Cao, \& Anderson, 2009; Costa et al., 2015).

In this study the L/D ratios obtained are considered high as suggested by Moon et al. (2011), a factor relevant for CNCs' applicability. The performance of reinforced materials depends on the efficiency with which the mechanical stress is transferred from an external energy source to the reinforcement phase through the matrix. In this way, the quantity and quality of the interfacial area becomes important. A high $\mathrm{L} / \mathrm{D}$ ratio improves the contact surface of the material with the matrix, therefore CNCs presenting a high L/D ratio have an enhanced ability to sustain uniformly the mechanical stress on the matrix (Klemm et al., 2011). In fact, it has been reported that cellulose structures with different $\mathrm{L} / \mathrm{D}$ ratio present different mechanical properties. One example is MCC that presents an elastic modulus in the axial direction of $25 \mathrm{GPa}$ while CNCs values can go up to $105 \mathrm{GPa}$ (Rusli \& Eichhorn, 2008).

Thus, the ultrasound treatment seems to be essential to obtain adequate CNCs, and longer ultrasound treatment times may allow obtaining CNCs with high L/D ratio.
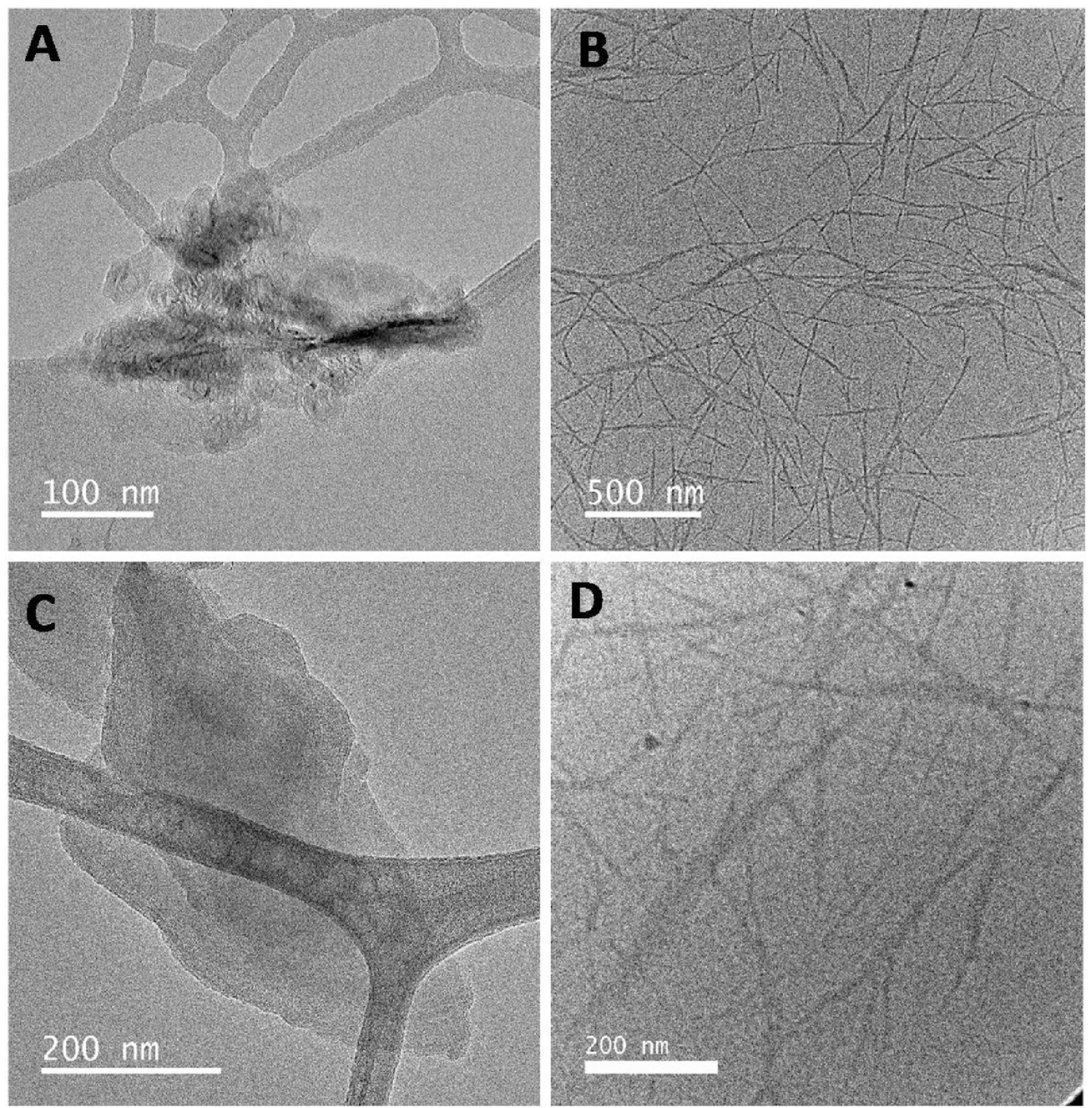

Fig. 2. Transmission electron microscopy of the samples obtained by acid hydrolysis of cellulose for $30 \mathrm{~min}\left(\mathrm{AH}_{30}\right)$ and $60 \mathrm{~min}\left(\mathrm{AH}_{60}\right)$, followed by further ultrasound treatment $\left(\mathrm{AH}_{30 \mathrm{~s}}\right.$ and $\mathrm{AH}_{600}$, respectively). (A) $\mathrm{AH}_{30}$; (B) $\mathrm{AH}_{305}$; (C) $\mathrm{AH}_{60}$; and (D) $\mathrm{AH}_{60 s}$. 


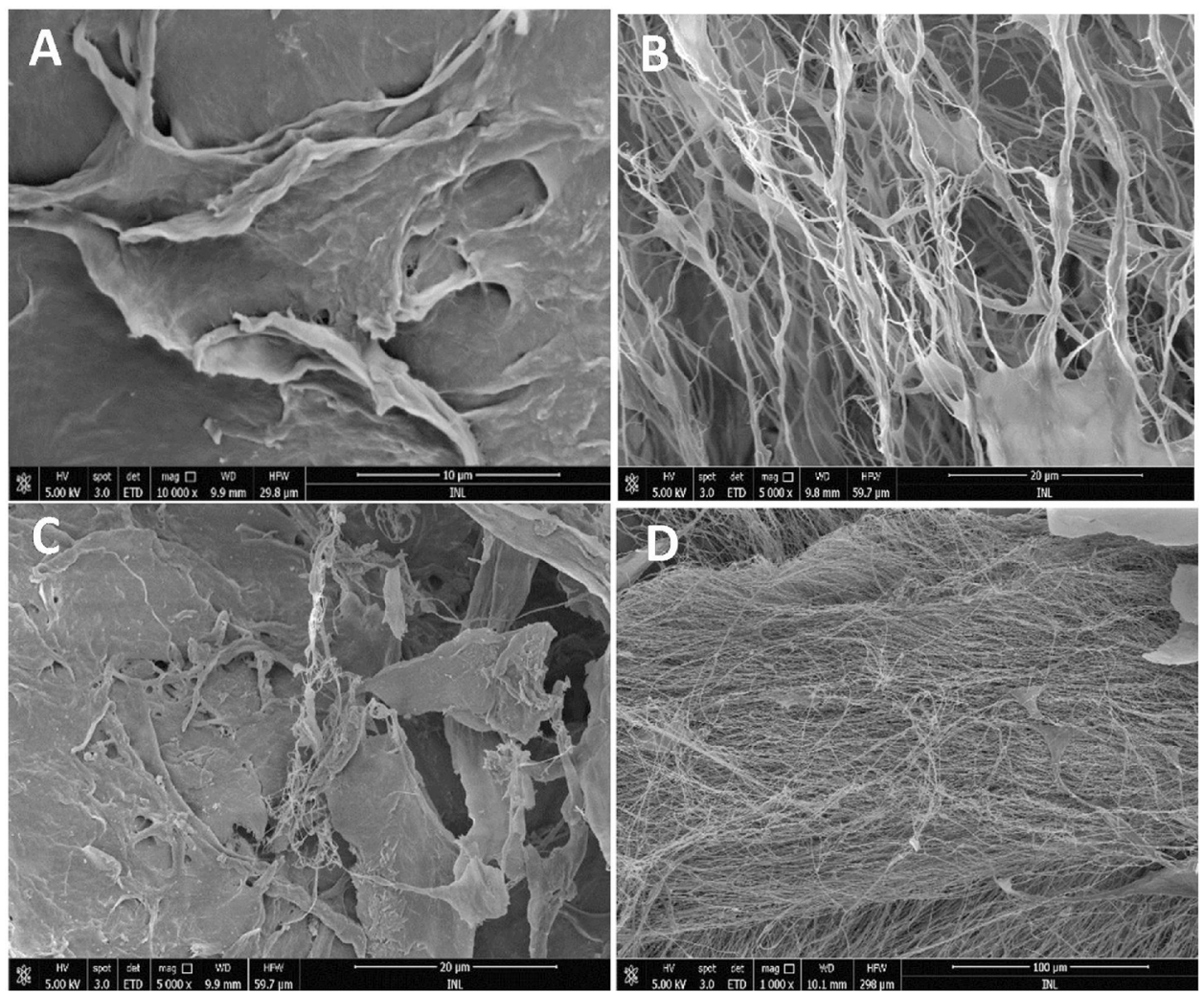

Fig. 3. Scanning electron microscopy of the samples obtained by acid hydrolysis of cellulose for $30 \mathrm{~min}\left(\mathrm{AH}_{30}\right)$ and $60 \mathrm{~min}\left(\mathrm{AH} \mathrm{H}_{60}\right)$, followed by further ultrasound

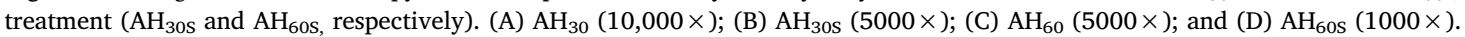

treatment (Fig. 4). The ultrasound treatment increased the dispersion stability and no precipitation was observed after 7 days of storage (CNC samples). In fact, ultrasound energy, transferred to cellulose chains through cavitation, gradually disintegrated the crystalline cellulose from micron-sized particles (MCC) into nano-sized particles (CNCs) (Chen et al., 2011; Tischer, Sierakowski, Westfahl Jr, \& Tischer, 2010) and thus increased suspensions stability. These results were also reported by Khawas and Deka (2016), which observed a reduction in the size of the nanofibers with a substantial increase in the dispersion of nanofiber suspension, after ultrasonic treatment.

\subsection{X-ray diffraction analysis}

The XRD patterns of UGP and PGP showed the maximum intensity of the diffraction peak of the (200) plane at $2 \theta=22.5^{\circ}$ (data not shown). Peaks around $15.0^{\circ}$ and $22.5^{\circ}$ (verified in cellulose-rich PGP) indicate typical pattern of cellulose I (Jiang \& Hsieh, 2015). Comparing the diffraction patterns between both samples, it is possible to observe well defined and high intensity peaks in the PGP diffractogram than in the UGP diffractogram, confirming the high cellulose amount (crystalline component) in the PGP sample, as observed in the chemical composition (Table 1).

Table 2 presents the CrI values for all samples, showing that crystallinity increased from UGP to PGP due to the cellulose purification mainly attributed to the removal of amorphous hemicellulose and lignin, leading to the realignment of cellulose molecules (Li et al., 2009). These CrI values are in agreement with cellulose isolated from garlic straw (68\%) (Kallel et al., 2016), rice (61.8\%) (Lu \& Hsieh, 2012a), wood (73.5\%) (Li \& Renneckar, 2011) and cotton (65\%) (Lu \& Hsieh, 2010). From the CrI values, it is possible to observe the increase in crystallinity in samples treated with acid hydrolysis $\left(\mathrm{AH}_{30}\right.$ and $\mathrm{AH}_{60}$ ), which is explained by the partial depolymerization and removal of the amorphous regions of the cellulose from the PGP sample. In this process the hydronium ions penetrate into the amorphous regions of cellulose promoting the hydrolytic cleavage of glycoside bonds, and thus releasing the individual crystallites. The realignment of monocrystals may occur during the aggregation forming the CNCs, leading to the increase of samples crystallinity (de Souza Lima \& Borsali, 2004; Li et al., 2009).

The CrI values also increased for longer treatments and with ultrasound treatment $\left(\mathrm{AH}_{30 \mathrm{~s}}\right.$ and $\mathrm{AH}_{60 \mathrm{~s}}$ samples). This indicates that the ultrasound breaks the amorphous regions remaining in the samples and also reorganizes and enriches the crystalline cellulose regions. From the XRD patterns, it was also possible to conclude that, during both the chemical and the ultrasound treatments, the crystalline structure of cellulose did not change, since all diffractograms presented pattern characteristic of cellulose I (results not shown).

\subsection{Thermogravimetric analysis}

Fig. 5 shows the thermogravimetric behavior reflecting the samples thermal stability. All samples present a small weight loss in the $25-150{ }^{\circ} \mathrm{C}$ region, corresponding to the evaporation of the absorbed water (Khawas \& Deka, 2016). Fig. 5A shows that the UGP components present an initial degradation temperature $\left(T_{\text {onset }}\right)$ around $254{ }^{\circ} \mathrm{C}$, due to the low decomposition temperature of hemicellulose, lignin, and pectin (Morán, Alvarez, Cyras, \& Vázquez, 2008), reaching the maximum degradation temperature $\left(T_{\max }\right)$ at $346^{\circ} \mathrm{C}$, representing the pyrolysis of cellulose. On the other hand, the PGP components showed $T_{\text {onset }}$ at about $275^{\circ} \mathrm{C}$ (mainly residual lignin, Table 1 ), with $T_{\max }$ at $347^{\circ} \mathrm{C}$. Thus, the highest $T_{\text {onset }}$ observed for PGP is associated with the removal of lignin (Alemdar \& Sain, 2008; Chen et al., 2011), as observed in chemical composition (Table 1) and higher CrI (Table 2) of PGP.

$\mathrm{AH}_{30}$ and $\mathrm{AH}_{60}$ samples presented a $T_{\max }$ of $364^{\circ} \mathrm{C}$ and $242.5^{\circ} \mathrm{C}$, respectively (Fig. 5B and C, respectively). It has been reported that the 

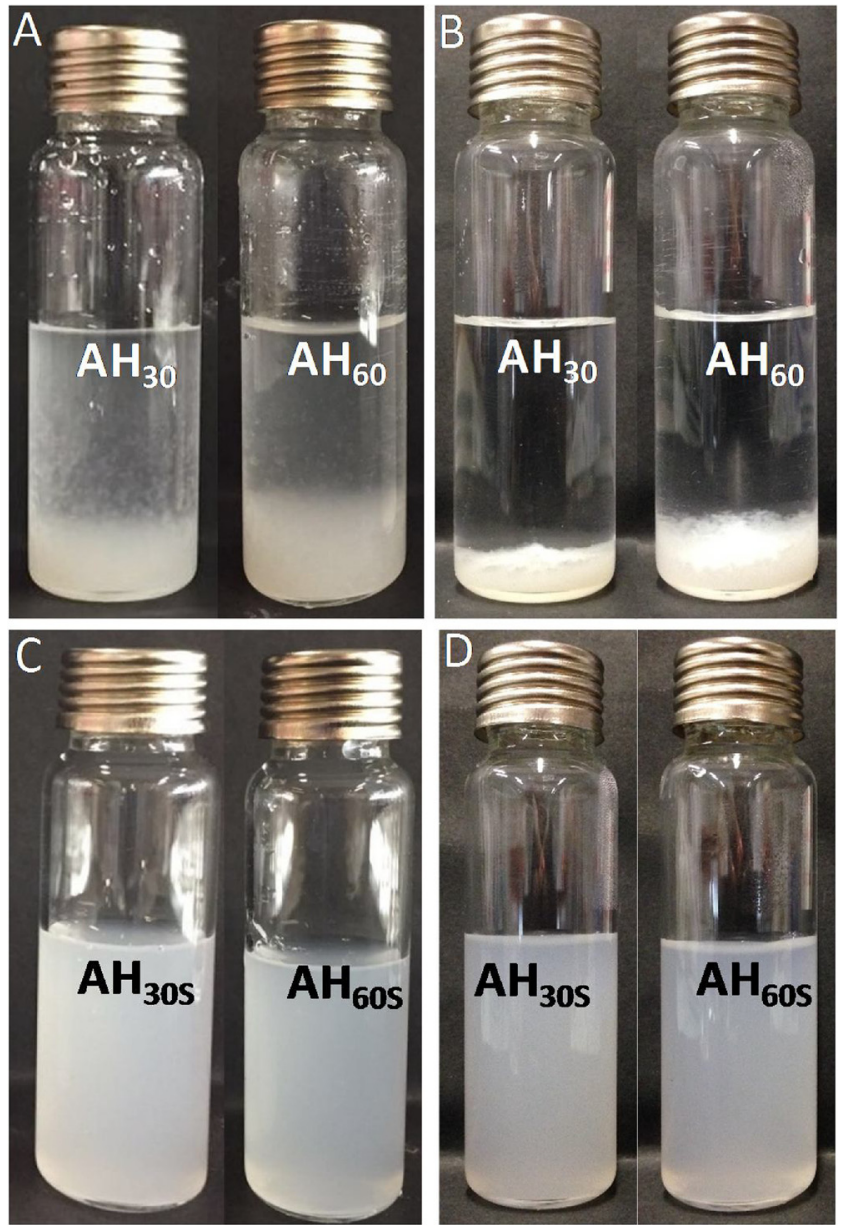

Fig. 4. Stability of the samples obtained by acid hydrolysis of cellulose for $30 \mathrm{~min}\left(\mathrm{AH}_{30}\right)$ and $60 \mathrm{~min}\left(\mathrm{AH}_{60}\right)$, followed by further ultrasound treatment $\left(\mathrm{AH}_{30 \mathrm{~S}}\right.$ and $\mathrm{AH}_{60 \mathrm{~S}}$, respectively) for until 7 days at $7{ }^{\circ} \mathrm{C}$. (A) $\mathrm{AH}_{30}$ and $\mathrm{AH}_{60}$ samples after $30 \mathrm{~min}$ of storage; (B) $\mathrm{AH}_{30}$ and $\mathrm{AH}_{60}$ samples after 7 days of storage; (C) $\mathrm{AH}_{30 \mathrm{~s}}$ and $\mathrm{AH}_{60 \mathrm{~s}}$ samples after 30 min of storage; and (D) $\mathrm{AH}_{30 \mathrm{~S}}$ and $\mathrm{AH}_{60 \mathrm{~s}}$ samples after 7 days of storage.

Table 2

Crystallinity index of untreated (UGP) and pretreated grape pomace (PGP), microcrystalline celluloses $\left(\mathrm{AH}_{30}\right.$ and $\left.\mathrm{AH}_{60}\right)$, and cellulose nanocrystals $\left(\mathrm{AH}_{30 \mathrm{~s}}\right.$ and $\left.\mathrm{AH}_{60 \mathrm{~s}}\right)$.

\begin{tabular}{ll}
\hline Samples & CrI (\%) \\
\hline UGP & 23.50 \\
PGP & 62.13 \\
$\mathrm{AH}_{30}$ & 65.45 \\
$\mathrm{AH}_{305}$ & 70.62 \\
$\mathrm{AH}_{60}$ & 68.89 \\
$\mathrm{AH}_{605}$ & 74.89 \\
\hline
\end{tabular}

activation energy of the degradation of cellulose is significantly reduced by the introduction of sulfate groups through the hydrolysis step with sulfuric acid (Jiang \& Hsieh, 2015; Roman \& Winter, 2004; Xie et al., 2016). The presence of sulfate groups is related to the increase of cellulose amount, acid concentration and time of hydrolysis (Roman \& Winter, 2004). Therefore, the lower $T_{\max }$ obtained for $\mathrm{AH}_{60}$ sample can be explained by the high amount of sulfate groups presented in this sample, due to the longer hydrolysis time used (60 $\mathrm{min}$ ).

Regarding the samples treated with ultrasound, $\mathrm{AH}_{30 \mathrm{~s}}$ had similar TG profile to the $\mathrm{AH}_{30}$, with the curves overlapping with $T_{\max }$ at $365^{\circ} \mathrm{C}$, indicating that ultrasound treatment did not affect the thermal stability

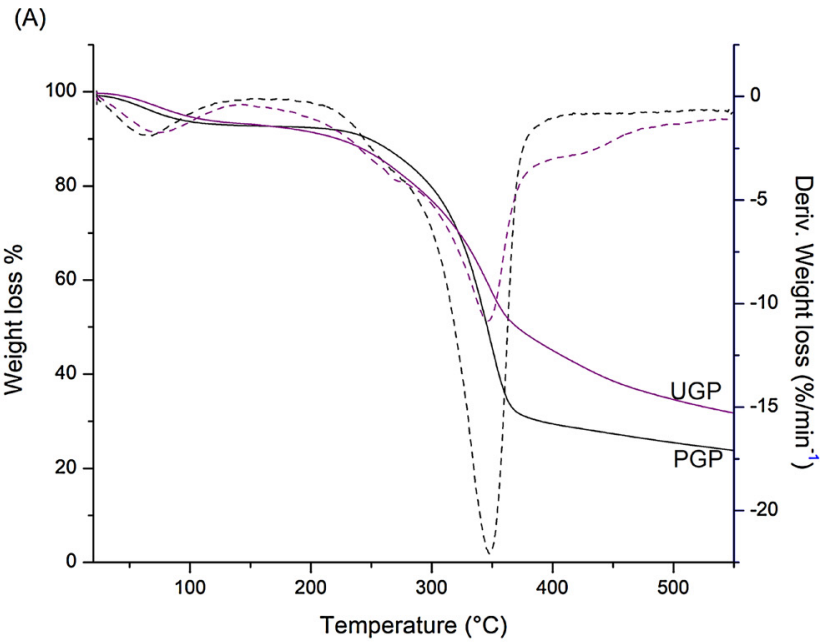

(B)
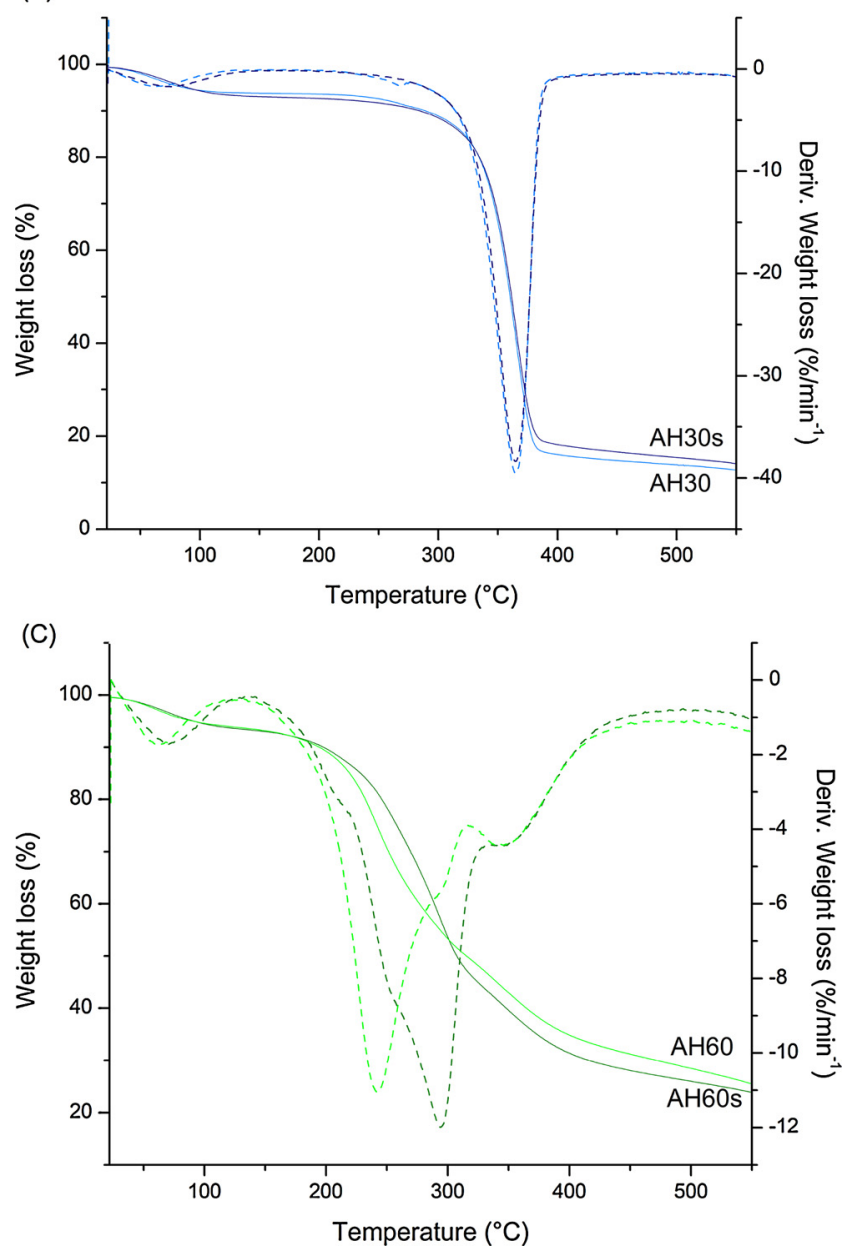

Fig. 5. Thermogravimetric (TG) and derivative thermogravimetric (DTG) curves of untreated (UGP) and pretreated (PGP) grape pomace, samples obtained by acid hydrolysis of cellulose for $30 \mathrm{~min}\left(\mathrm{AH}_{30}\right)$ and $60 \mathrm{~min}\left(\mathrm{AH}_{60}\right)$, and samples obtained by acid hydrolysis of cellulose for $30 \mathrm{~min}\left(\mathrm{AH}_{30}\right)$ and $60 \mathrm{~min}$ $\left(\mathrm{AH}_{60}\right)$ followed by further ultrasound treatment $\left(\mathrm{AH}_{30 \mathrm{~s}}\right.$ and $\mathrm{AH}_{60 \text { s }}$, respectively). (A) UGP and PGP; (B) $\mathrm{AH}_{30}$ and $\mathrm{AH}_{305}$; (C) $\mathrm{AH}_{60}$ and $\mathrm{AH}_{605}$. The dashed curves represent a derivative weight loss.

of the sample acid hydrolyzed for $30 \mathrm{~min}$ (Fig. 5B). In the samples obtained with $60 \mathrm{~min}$ of acid hydrolysis, two main degradation events between $200{ }^{\circ} \mathrm{C}$ and $400{ }^{\circ} \mathrm{C}$ were observed, indicating different degradation levels due to sulfate groups in the cellulose structure. 


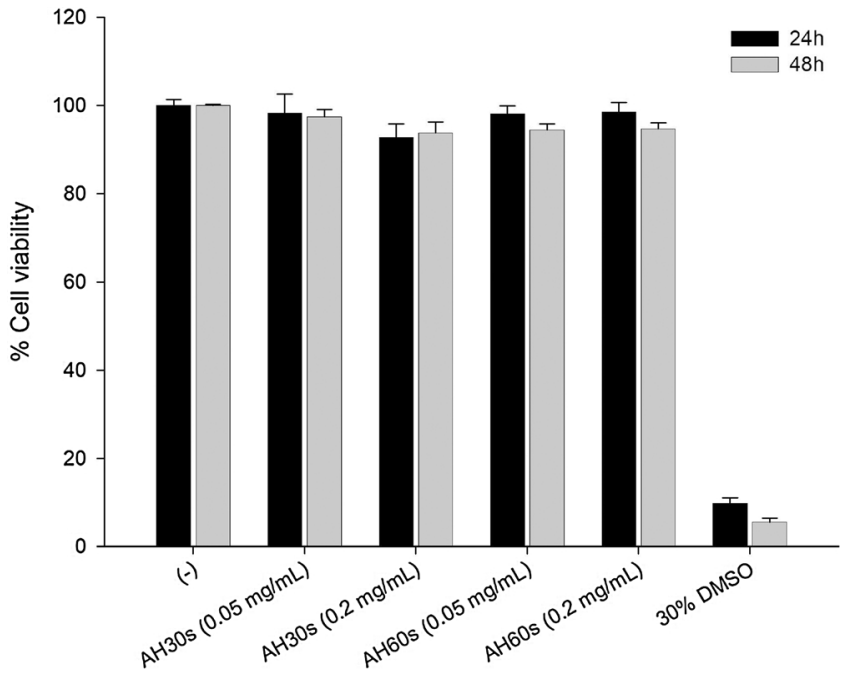

Fig. 6. Cellular viability (\%) of samples obtained by acid hydrolysis of cellulose for $30 \mathrm{~min}$ and $60 \mathrm{~min}$ followed by further ultrasound treatment $\mathrm{AH}_{30 \mathrm{~s}}$ and $\mathrm{AH}_{60 \mathrm{~s}}$, respectively) ( 0.05 and $0.20 \mathrm{mg} / \mathrm{mL}$ ) after 24 and $48 \mathrm{~h}$ of incubation. Controls: ( - ) cells incubated with $20 \%$ ultrapure water (negative control); cells incubated with $30 \%$ of DMSO (dimethyl sulfoxide, death control). Data show mean $+\mathrm{SD}, \mathrm{n}=8$, two independent assays.

Moreover, the $\mathrm{AH}_{60 \mathrm{os}}$ showed an increase in $T_{\max }\left(298{ }^{\circ} \mathrm{C}\right)$ when compared to $\mathrm{AH}_{60}$ (Fig. 5C). Two degradation events were also reported by Martínez-Sanz et al. (2011) and Silvério, Flauzino Neto, Dantas, and Pasquini (2013) in CNCs samples. According to these authors the first peak (in the degradation region) may correspond to the degradation of amorphous regions which are, therefore, more accessible and sulfated, and the second peak temperature refers to the degradation of cellulose less accessible to acid uptake which, not being sulfated, tends to be more thermally stable.

Results show that thermal stability of the MCC and CNC samples can be affected by the treatment conditions, suggesting that samples obtained with $60 \mathrm{~min}$ of acid hydrolysis $\left(\mathrm{AH}_{60}\right.$ and $\left.\mathrm{AH}_{60 \mathrm{~S}}\right)$ may be limited to polymer matrices that require processing temperatures around $250^{\circ} \mathrm{C}$.

\subsection{Cytotoxicity}

The cytotoxicity of materials is routinely evaluated using in vitro methodologies. Cell lines are often cultivated in contact with test materials, and after a variable period of time, the cellular metabolic activity, proliferation and/or death rates are measured. In this study, the commercial PrestoBlue, a resazurin-based solution, was used to assess the cellular viability of human colon epithelial cells (Caco-2) after incubation with $\mathrm{CNCs}\left(\mathrm{AH}_{30 \text { s }}\right.$ and $\mathrm{AH}_{60 \text { s }}$ samples), at different concentrations.

Fig. 6 shows that $\mathrm{CNCs}\left(\mathrm{AH}_{30 \mathrm{~s}}\right.$ and $\left.\mathrm{AH}_{60 \mathrm{~S}}\right)$ had no effect on the metabolic activity of Caco-2 cells. All samples exhibited high cell viability up to $48 \mathrm{~h}$ of incubation showing the biocompatibility of the produced CNCs. Few reports address the biocompatibility of CNCs (Lin \& Dufresne, 2014). Some authors reveal no cytotoxic effects. Dong, Hirani, Colacino, Lee, and Roman (2012) reported no cytotoxic effect of plant-derived CNCs for a variety of mammalian cells in the concentration range of $0-0.05 \mathrm{mg} / \mathrm{mL}$, up to $48 \mathrm{~h}$. Other authors observed a dosedependent cytotoxicity of CNCs. As an example, Ni et al. (2012) reported the cytotoxicity of CNCs prepared from cotton linters, presented as cellulose nanowhiskers. Low cytotoxicity was observed at low concentrations (up to $2.0 \mathrm{mg} / \mathrm{mL}$ ), increasing for higher concentrations $(10 \mathrm{mg} / \mathrm{mL})$. In this work, stable dispersions were tested $(0.05$ and $0.2 \mathrm{mg} / \mathrm{mL}$ ) to avoid CNCs precipitation over the cells (data not shown) that may result in artefactual effects (OECD, 2016).
The increasing production of CNCs from different sources and their application in food has elicited ample discussion about the potential risks of these materials to human health (Seaton \& Donaldson, 2005). The same properties that make nanomaterials interesting and attractive, such as the reduced size of the particle, its differentiated form, and the large surface area, may on the other hand be responsible for their potentially toxic effects (Paschoalino, Marcone, \& Jardim, 2010). Thus, it is important to assess the toxicity risks of nanomaterial exposure via ingestion. The results of this study provide a first indication that the tested CNCs produced from grape pomace are not toxic, and thus are appropriate for use in food or pharmaceutical applications.

\section{Conclusion}

The present study demonstrated the potential of the grape pomace, an abundant agroindustrial residue, to produce cellulose nanocrystals (CNCs). A key requirement for high CNCs yield is the efficient removal of non-cellulosic components such as lignin and hemicellulose from UGP, resulting in a material with high cellulose content. This work demonstrated that the acid hydrolysis led to the production of microcrystalline structures from the purified cellulose, and also considered the ultrasound treatment as an essential step for the CNCs production. The CNCs obtained were stable in solution over seven days, presenting high aspect ratio and crystallinity. These features are determinant for improving the dispersion capacity of these nanocrystals into food structures or polymeric matrixes, allowing their application as reinforcing materials in packaging materials or gels.

The production scheme presented here to obtain CNCs from grape pomace, on one hand, can contribute to reduce the waste management costs of the wine industry, while diversifying the source of materials for CNCs production. On the other hand, these non-toxic natural materials can provide a new opportunity for their use on food and pharmaceutical fields, and these dispersion capacity suggests possible application as reinforcing materials. Certainly, combined with advanced nanotechnologies such as electrospinning and electrospraying, CNCs-based nanocomposites can find even more applications in many fields (Li, Zheng, \& Yu, 2017; Wang et al., 2017; Yu, Li, Zhang, \&Williams, 2017).

\section{Acknowledgments}

This study was supported by the Coordenacão de Aperfeiçoamento Pessoal de Ensino Superior (CAPES), Embrapa Agroindústria de Alimentos (EMBRAPA), FP7-PEOPLE-2013-IRSES-611493 (BiValBi Biotechnologies to Valorise the regional food Biodiversity in Latin America) and Portuguese Foundation for Science and Technology (FCT) under the scope of the strategic funding of UID/BIO/04469/2013 unit and COMPETE 2020 (POCI-01-0145-FEDER-006684) and BioTecNorte operation (NORTE-01-0145-FEDER-000004) funded by the European Regional Development Fund under the scope of Norte2020-Programa Operacional Regional do Norte. The work was also supported by the Norte Regional Operational Program 2014-2020 (Norte2020) through the European Regional Development Fund (ERDF) Nanotechnology based functional solutions (NORTE-01-0145-FEDER-000019). Michele Michelin is a recipient of a FCT fellowship (SFRH/BPD/100786/2014). The authors thank Paula Pereira for the technical support.

\section{References}

Alemdar, A., \& Sain, M. (2008). Isolation and characterization of nanofibers from agricultural residues - Wheat straw and soy hulls. Bioresource Technology, 99(6), 1664-1671. http://dx.doi.org/10.1016/j.biortech.2007.04.029.

Ansar Ahmed, S., Gogal, R. M., \& Walsh, J. E. (1994). A new rapid and simple nonradioactive assay to monitor and determine the proliferation of lymphocytes: An alternative to [3H]thymidine incorporation assay. Journal of Immunological Methods, 170(2), 211-224. http://dx.doi.org/10.1016/0022-1759(94)90396-4.

Beres, C., Simas-Tosin, F. F., Cabezudo, I., Freitas, S. P., Iacomini, M., Mellinger-Silva, C., et al. (2016). Antioxidant dietary fibre recovery from Brazilian Pinot noir grape pomace. Food Chemistry, 201, 145-152. http://dx.doi.org/10.1016/j.foodchem.2016. 
01.039 .

Brinchi, L., Cotana, F., Fortunati, E., \& Kenny, J. M. (2013). Production of nanocrystalline cellulose from lignocellulosic biomass: Technology and applications. Carbohydrate Polymers, 94(1), 154-169. http://dx.doi.org/10.1016/j.carbpol.2013.01.033.

Chen, Y., Liu, C., Chang, P. R., Cao, X., \& Anderson, D. P. (2009). Bionanocomposites based on pea starch and cellulose nanowhiskers hydrolyzed from pea hull fibre: Effect of hydrolysis time. Carbohydrate Polymers, 76(4), 607-615. http://dx.doi.org/10. 1016/j.carbpol.2008.11.030.

Chen, W., Yu, H., Liu, Y., Chen, P., Zhang, M., \& Hai, Y. (2011). Individualization of cellulose nanofibers from wood using high-intensity ultrasonication combined with chemical pretreatments. Carbohydrate Polymers, 83(4), 1804-1811. http://dx.doi. org/10.1016/j.carbpol.2010.10.040.

Costa, L. A. S., de Assis, D. J., Gomes, G. V. P., Da Silva, J. B. A., Fonsêca, A. F., \& Druzian, J. I. (2015). Extraction and characterization of nanocellulose from corn stover. Materials Today: Proceedings, 2(1), 287-294. http://dx.doi.org/10.1016/j.matpr. 2015.04 .045$.

de Souza Lima, M. M., \& Borsali, R. (2004). Rodlike cellulose microcrystals: structure, properties, and applications. Macromolecular Rapid Communications, 25, 771-787. http://dx.doi.org/10.1002/marc.200300268.

Dong, S., Hirani, A. A., Colacino, K. R., Lee, Y. W., \& Roman, M. (2012). Cytotoxicity and cellular uptake of cellulose nanocrystals. Nano LIFE, 2(3), 1241006. http://dx.doi. org/10.1142/S1793984412410061.

Goula, A. M., Thymiatis, K., \& Kaderides, K. (2016). Valorization of grape pomace: Drying behavior and ultrasound extraction of phenolics. Food and Bioproducts Processing, 100, 132-144. http://dx.doi.org/10.1016/j.fbp.2016.06.016.

Hsieh, Y. L. (2013). Cellulose nanocrystals and self-assembled nanostructures from cotton, rice straw and grape skin: A source perspective. Journal of Materials Science, 48(22), 7837-7846. http://dx.doi.org/10.1007/s10853-013-7512-5.

Jiang, F., \& Lo Hsieh, Y. (2013). Chemically and mechanically isolated nanocellulose and their self-assembled structures. Carbohydrate Polymers, 95(1), 32-40. http://dx.doi. org/10.1016/j.carbpol.2013.02.022.

Jiang, F., \& Lo Hsieh, Y. (2015). Cellulose nanocrystal isolation from tomato peels and assembled nanofibers. Carbohydrate Polymers, 122, 60-68. http://dx.doi.org/10. 1016/j.carbpol.2014.12.064.

Johar, N., Ahmad, I., \& Dufresne, A. (2012). Extraction, preparation and characterization of cellulose fibres and nanocrystals from rice husk. Industrial. Crops and Products, 37, 93-99. http://dx.doi.org/10.1016/j.indcrop.2011.12.016.

Kallel, F., Bettaieb, F., Khiari, R., García, A., Bras, J., \& Chaabouni, S. E. (2016). Isolation and structural characterization of cellulose nanocrystals extracted from garlic straw residues. Industrial Crops and Products, 87, 287-296. http://dx.doi.org/10.1016/j. indcrop. 2016.04.060.

Khawas, P., \& Deka, S. C. (2016). Isolation and characterization of cellulose nanofibers from culinary banana peel using high-intensity ultrasonication combined with chemical treatment. Carbohydrate Polymers, 137, 608-616. http://dx.doi.org/10.1016/j. carbpol.2015.11.020.

Klemm, D., Kramer, F., Moritz, S., Lindström, T., Ankerfors, M., \& Gray, D. (2011) Nanocelluloses: A new family of nature-based materials. Angewandte Chemie International Edition, 50(24), 5438-5466. http://dx.doi.org/10.1002/anie. 201001273.

Li, Q., \& Renneckar, S. (2011). Supramolecular structure characterization of molecularly thin cellulose I nanoparticles. Biomacromolecules, 12(3), 650-659. http://dx.doi.org/ 10.1021/bm101315y.

Li, R., Fei, J., Cai, Y., Li, Y., Feng, J., \& Yao, J. (2009). Cellulose whiskers extracted from mulberry: A novel biomass production. Carbohydrate Polymers, 76(1), 94-99. http:// dx.doi.org/10.1016/j.carbpol.2008.09.034.

Li, W., Yue, J., \& Liu, S. (2012). Preparation of nanocrystalline cellulose via ultrasound and its reinforcement capability for poly(vinyl alcohol) composites. Ultrasonics Sonochemistry, 19(3), 479-485. http://dx.doi.org/10.1016/j.ultsonch.2011.11.007.

Li, X.-Y., Zheng, Z.-B., \& Yu, D.-G. (2017). Electrosprayed sperical ethylcellulose nanoparticles for an improved sustained-release profile of anticancer drug. Cellulose, 24(12), 5551-5564.

Lin, N., \& Dufresne, A. (2014). Nanocellulose in biomedicine: Current status and future prospect. European Polymer Journal, 59, 302-325. http://dx.doi.org/10.1016/j eurpolymj.2014.07.025

Lu, P., \& Hsieh, Y. (2010). Preparation and properties of cellulose nanocrystals: Rods, spheres, and network. Carbohydrate Polymers, 82, 329-336. http://dx.doi.org/10. 1016/j.carbpol.2010.04.073.

Lu, P., \& Hsieh, Y.-L. (2012a). Preparation and characterization of cellulose nanocrystals from rice straw. Carbohydrate Polymers, 87(1), 564-573. http://dx.doi.org/10.1016/ j.carbpol.2011.08.022

Lu, P., \& Lo Hsieh, Y. (2012b). Cellulose isolation and core-shell nanostructures of cellulose nanocrystals from chardonnay grape skins. Carbohydrate Polymers, 87(4), 2546-2553. http://dx.doi.org/10.1016/j.carbpol.2011.11.023.

Market and Market (2018). Source. https://www.marketsandmarkets.com/ PressReleases/nanocellulose.asp. [Accessed: 11 February 2018].

Martínez-Sanz, M., Lopez-Rubio, A., \& Lagaron, J. M. (2011). Optimization of the nanofabrication by acid hydrolysis of bacterial cellulose nanowhiskers. Carbohydrate Polymers, 85(1), 228-236. http://dx.doi.org/10.1016/j.carbpol.2011.02.021.

Martins, D. F., De Souza, A. B., Henrique, M. A., Silvério, H. A., Pires, W., Neto, F., et al. (2015). The influence of the cellulose hydrolysis process on the structure of cellulose nanocrystals extracted from capim mombaça (Panicum maximum). Industrial Crops and Products Journal, 65, 496-505. http://dx.doi.org/10.1016/j.indcrop.2014.10. 035.

Minjares-Fuentes, R., Femenia, A., Garau, M. C., Candelas-Cadillo, M. G., Simal, S., \& Rosselló, C. (2016). Ultrasound-assisted extraction of hemicelluloses from grape pomace using response surface methodology. Carbohydrate Polymers, 138, 180-191. http://dx.doi.org/10.1016/j.carbpol.2015.11.045

Moon, R. J., Martini, A., Nairn, J., Simonsen, J., \& Youngblood, J. (2011). Cellulose nanomaterials review: Structure, properties and nanocomposites. Chemical Society Reviews, 40(7), 3941-3994. http://dx.doi.org/10.1039/c0cs00108b.

Morán, J. I., Alvarez, V. A., Cyras, V. P., \& Vázquez, A. (2008). Extraction of cellulose and preparation of nanocellulose from sisal fibers. Cellulose, 15, 149-159. http://dx.doi. org/10.1007/s10570-007-9145-9.

Moriana, R., Vilaplana, F., \& Ek, M. (2016). Cellulose nanocrystals from forest residues as reinforcing agents for composites: a study from macro- to nano-dimensions. Carbohydrate Polymers, 139, 139-149. http://dx.doi.org/10.1016/j.carbpol.2015.12 020.

Mueller, S., Weder, C., \& Foster, E. J. (2014). Isolation of cellulose nanocrystals from pseudostems of banana plants. RSC Advances, 4(2), 907-915. http://dx.doi.org/10. 1039/c3ra46390g.

do Nascimento, D. M., Dias, A. F., de Araújo, C. P., Junior, de F. Rosa, M., Morais, J. P. S. \& de Figueirêdo, M. C. B. (2016). A comprehensive approach for obtaining cellulose nanocrystal from coconut fiber. Part II: Environmental assessment of technological pathways. Industrial Crops and Products, 93, 58-65. http://dx.doi.org/10.1016/j. indcrop.2016.02.063.

Ni, H., Zeng, S., Wu, J., Cheng, X., Luo, T., Wang, W., et al. (2012). Cellulose nanowhiskers: Preparation, characterization and cytotoxicity evaluation. Bio-Medical Materials and Engineering, 22(1-3), 121-127. http://dx.doi.org/10.3233/BME-20120697.

Nociari, M. M., Shalev, a., Benias, P., \& Russo, C. (1998). A novel one-step, highly sensitive florometric assay to evaluate cell-mediated cytotoxicity. Journal of Immunological Methods, 213(2), 157-167.

Nowak, A., Sójka, M., Klewicka, E., Lipińska, L., Klewicki, R., \& Kołodziejczyk, K. (2017) Ellagitannins from Rubus Idaeus L. exert geno- and cytotoxic effects against human colon adenocarcinoma cell line caco-2. Journal of Agricultural and Food Chemistry, 65(14), 2947-2955. http://dx.doi.org/10.1021/acs.jafc.6b05387.

OECD (2016). Organization for economic co-operation and development. Guideline 473. [adopted 29 July]

Oun, A. A., \& Rhim, J.-W. (2015). Effect of post-treatments and concentration of cotton linter cellulose nanocrystals on the properties of agar-based nanocomposite films. Carbohydrate Polymers, 134, 20-29. http://dx.doi.org/10.1016/j.carbpol.2015.07. 053.

Paschoalino, M. P., Marcone, G. P. S., \& Jardim, W. F. (2010). Os Nanomateriais E a Questão Ambiental. Química Nova, 33(2), 421-430. http://dx.doi.org/10.1590/ S0100-40422010000200033.

Peng, Y., Gardner, D. J., \& Han, Y. (2012). Drying cellulose nanofibrils: In search of a suitable method. Cellulose, 19(1), 91-102. http://dx.doi.org/10.1007/s10570-0119630-z.

Prasad, R., Bhattacharyya, A., \& Nguyen, Q. D. (2017). Nanotechnology in sustainable agriculture: Recent developments, challenges, and perspectives. Frontiers in Microbiology, 8(1014), 1-13. http://dx.doi.org/10.3389/fmicb.2017.01014.

Reddy, J. P., \& Rhim, J.-W. (2014). Characterization of bionanocomposite films prepared with agar and paper-mulberry pulp nanocellulose. Carbohydrate Polymers, 110, 480-488. http://dx.doi.org/10.1016/j.carbpol.2014.04.056.

Roman, M., \& Winter, W. T. (2004). Effect of sulfate groups from sulfuric acid hydrolysis on the thermal degradation behavior of bacterial cellulose. Biomacromolecules, 5(5), 1671-1677. http://dx.doi.org/10.1021/bm034519+.

Rosa, M. F., Medeiros, E. S., Malmonge, J. A., Gregorski, K. S., Wood, D. F., Mattoso, L. H. C., et al. (2010). Cellulose nanowhiskers from coconut husk fibers: Effect of preparation conditions on their thermal and morphological behavior. Carbohydrate Polymers, 81(1), 83-92. http://dx.doi.org/10.1016/j.carbpol.2010.01.059.

Rusli, R., \& Eichhorn, S. J. (2008). Determination of the stiffness of cellulose nanowhiskers and the fiber-matrix interface in a nanocomposite using Raman spectroscopy. Applied Physics Letters, 93(3), http://dx.doi.org/10.1063/1.2963491.

Seaton, A., \& Donaldson, K. (2005). Nanoscience nanotoxicology, and the need to think small. The Lancet, 18, 923-924.

Segal, L., Creely, J. J., Martin, A. E., Jr., \& Conrad, C. M. (1959). Empirical method for estimating the degree of crystallinity of native cellulose using the X-ray diffractometer. Textile Research Journal, 29(10), 786-794.

Silvério, H. A., Flauzino Neto, W. P., Dantas, N. O., \& Pasquini, D. (2013). Extraction and characterization of cellulose nanocrystals from corncob for application as reinforcing agentin nanocomposites. Industrial Crops and Products, 44, 427-436. http://dx.doi. org/10.1016/j.indcrop.2012.10.014.

Sluiter, A., Hames, B., Ruiz, R., Scarlata, C., Sluiter, J., Templeton, D., et al. (2008). Determination of structural carbohydrates and lignin in biomass. NREL - LAP. Technical Report NREL/TP-510-42618.

TAPPI (2011). Standard terms and their definition for cellulose nanomaterial. WI 3021 [Retrieved: September 1, 2017, from http://www.tappi.org].

de Teixeira, E. M., Bondancia, T. J., Teodoro, K. B. R., Corrêa, A. C., Marconcini, J. M., \& Mattoso, L. H. C. (2011). Sugarcane bagasse whiskers: Extraction and characterizations. Industrial Crops and Products, 33(1), 63-66. http://dx.doi.org/10.1016/j. indcrop.2010.08.009.

Teixeira, A., Baenas, N., Dominguez-perles, R., Barros, A., \& Rosa, E. (2014). Natural bioactive compounds from winery by-products as health promoters: A review. International Journal of Molecular Sciences, 15, 15638-15678. http://dx.doi.org/10. 3390/ijms150915638.

Thoorens, G., Krier, F., Leclercq, B., Carlin, B., \& Evrard, B. (2014). Microcrystalline cellulose, a direct compression binder in a quality by design environment - A review. International Journal of Pharmaceutics, 473(1-2), 64-72. http://dx.doi.org/10.1016/j. ijpharm.2014.06.055.

Tischer, P. C. S. F., Sierakowski, M. R., Westfahl, H., Jr., \& Tischer, C. A. (2010). Nanostructural reorganization of bacteria cellulose by ultrasonic treatment. 
Biomacromolecules, 11(5), 1217-1224.

Wang, Q., Yu, D.-G., Zhang, L.-L., Liu, X.-K., Deng, Y.-C., \& Zhao, M. (2017). Electrospun hypromellose-based hydrophilic composites for rapid dissolution of poorly watersoluble drug. Carbohydrate Polymers, 174, 617-625.

Xie, J., Hse, C.-Y., De Hoop, C. F., Hu, T., Qi, J., \& Shupe, T. F. (2016). Isolation and characterization of cellulose nanofibers from bamboo using microwave liquefaction combined with chemical treatment and ultrasonication. Carbohydrate Polymers, 151, 725-734. http://dx.doi.org/10.1016/j.carbpol.2016.06.011.
Xu, M., McCanna, D. J., \& Sivak, J. G. (2015). Use of the viability reagent PrestoBlue in comparison with alamarBlue and MTT to assess the viability of human corneal epithelial cells. Journal of Pharmacological and Toxicological Methods, 71, 1-7. http://dx. doi.org/10.1016/j.vascn.2014.11.003.

Yu, D.-G., Li, J.-J., Zhang, M., \& Williams, G. R. (2017). High-quality Janus nanofibers prepared using three-fluid electrospinning. Chemical Communications, 53, 4542-4545. http://dx.doi.org/10.1039/C7CC01661A. 